\title{
RAZÓN Y NOTAS: HISTORIA DE UNA DISONANCIA
}

J. Javier Goldáraz Gainza

La Revolución Científica del s. xvil afectó de forma muy diferente a las diversas ciencias. Un caso especial lo constituye la teoria musical. Esta heredó del s. xvi una serie de problemas - la inestabilidad de la afinación justa, el criterio de distinción entre consonancia y disonancia, el estatus de la cuarta, etc. - que, lejos de solucionarse en el xvir con la asunción del nuevo paradigma fisico, se hicieron más virulentos, quedando como prácticamente irresolubles. Es entonces cuando se establece de forma plena la distinción de la música como arte y como ciencia.

Vamos a atender a uno de estos problemas, el llamado de "la consonancia de la cuarta" y explorar los dos tratamientos diferentes que nos ofrece Descartes antes y después de la asunción por parte de éste de la teoria galileana de la coincidencia de las ondas sonoras como criterio de explicación de los diferentes grados de consonancia y disonancia.

Cuando nosotros escuchamos varias notas, a la vez o sucesivamente, podemos estimar que su combinación resulta más o menos agradable. Pero si además, como ocurre en Occidente desde Pitágoras, es posible una cuantificación matemática exacta de las relaciones entre esos sonidos, disponemos de un doble criterio para juzgar el grado de placer que su combinación nos produce: uno sensorial y otro racional. Podemos "medir" el grado de consonancia de un intervalo sensorialmente, "a oido" o racionalnente, según que los números de su razón sean más sencillos, es decir, se acerquen más a la unidad. Pero ¿qué ocurre si lu mcional y sensorial disienten? ¿Qué criterio debe prevalecer? Es lo que sucedia con el intervalo de cuarta en la época de Descartes.

El intervalo de cuarta, de razón 4/3 (do-fa, sol-do, etc.), estaba bien establecido en la teoria musical ya desde tiempos de Pitágonas como perteneciente de pleno derecho, junto a la octava y la quinta, al reducido campo de las consonancias. Pero desde principios del s. xvi comienza a ser desplazado por otro intervalo de "menor categoria" racional, la tercera mayor de razón $5 / 4$, menos simple, más alejada de la unidad pero sensorialmente más consonante. ¿Como es esto posible?

En el Compendium, el enfoque cartesiano es todavía fundamentalmente de indole matemático (a pesar de la importancia concedida al aspecto físico de la resonancia de la octava). Tras considerar los intervalos de octava y quinta, dirá Descartes acerca de la cuarta:

Esta es la unás improductiva de todas las consonancias, y nunca se emplea en las cantinelas a no ser por accidente, o con la ayuda de otras (...) porque está tan próxima a la quinta que, frente a la suavidad de esta, pierde toda su gracia. (...) la cuarta le será muy desagradable, como si luese projectada sólo la sombra en lugar del cuerpo, o una imager en lugar del objeto en si.

Con la excusa de que al escucharse una nota, se oye igualmente el primer armónicu, es decir, su octava, considera que la tercera mayor (ditono), está formada por números menores que la cuarta y es por tanto un intervalo mas perfecto, es decir, más consonante. El truco de Descartes es comparar la cuarta (3/4) con la décima (tercera mayor más uctava. 2/5); es decir, añade una octava a la tercera y no a la cuarta. Esto no deja de ser una burda justificación numérica.

Pero doce anos mas tarde, en 1629, Descartes acaba de adlierirse a los nuevos modos de explicación tĩsica de la consonancia establecidos fundamentalmente por Galileo y Mersenne 
basados en la coincidencia de ondas sonoras y armónicos que no hacen sino confirmar con mayor vigor los antiguos planteamientos aritméticos de los siglos pasados. Descartes no puede ya mantener la posición anterior $y$ ante la evidencia fisica de una mayor perfección de la cuarta frente al criterio estético que prefiere la tercera mayor, se ve obligado a distinguir dos criterios, el cientifico (lo "dulce") y el estético (lo "agradable") que a veces, como en este caso, no coinciden. Asi, escribe a Mersenne en 1630:

Hay que sehalar que todo este cálculo solamente sirve para mostrar qué consonancias son las más simples o, si preferis, las más suaves (douces) y perfectas, pero no las más agradables (ogreables); (...). Para determinar qué es más agradable, hay que considerar la capacidad del oyente que, como el gusto, varia segün las personas.

$\mathrm{Y}$ al ano siguiente:

En cuanto a la suavidad de las consonancias hay que distinguir dos cosas, a saber, lo que las hace más simples y consonantes por un lado y lo que las lace mas agradables al oido. En cuanto a qué las hace más agradables, depende de donde se las emplee. (...) de modo que no sabria asegurar de forma absoluta que una consonancia sea mis agradable que otra. (...) Pero puede decirse de forma absoluta qué consonancias son las mis simples y consonantes porque esto no depende mảs que de que sus sonidos se unan más unos con otros y que se aproximen más a la naturaleza del unisono; de forma que se puede decir de forma absoluta que la cuarta es mas consonante que la tercera mayor, aunque en general no sea tan agradable, corno el cassis es más dulce que las olivas pero no tan agradable para nuestro gusto.

Descartes vuelve a conceder mayor perfección a la cuarta que a la tercera pero a costa de tener que separar radicalmente la esfera cientifica y la estética. Tal separación continuará a lo largo de su vida hasta el punto de negar validez objetiva a las reglas de composición que pretendia haber usado el cartesiano sacerdote holandés J. A. Ban en la famosa polémica con el, en su época, famoso compositor A. Boisset, o al negar las pretensiones de Mersenne de crear un sistema mecánico combinatorio que nos garantice la creación de la melodia más bella posible. 